\title{
Commentary: The devil you know and the devil you don't
}

\author{
Danielle Gottlieb Sen, MS, MD, MPH, ${ }^{\mathrm{a}, \mathrm{b}}$ and Thomas R. Kimball, MD
}

\author{
From the a'Children's Hospital New Orleans, Louisiana and Louisiana State University Health Sciences Center, \\ New Orleans, La; and ${ }^{\mathrm{b}}$ Monroe Carell Children's Hospital at Vanderbilt University, Nashville, Tenn. \\ Disclosures: Authors have nothing to disclose with regard to commercial support. \\ Received for publication March 19, 2019; accepted for publication March 20, 2019; available ahead of print May \\ 23, 2019. \\ Address for reprints: Danielle Gottlieb Sen, MS, MD, MPH, Children's Hospital New Orleans, ACC Suite 4102, \\ 200 Henry Clay Ave, New Orleans, LA 70118 (E-mail: danielle.gottliebsen@1cmchealth.org). \\ J Thorac Cardiovasc Surg 2019;158:835-6 \\ $0022-5223 / \$ 36.00$ \\ Copyright (C) 2019 by The American Association for Thoracic Surgery \\ https://doi.org/10.1016/j.jtcvs.2019.03.106
}

Anomalous aortic origin of the coronary arteries (AAOCA) presents difficult management decisions because of its low prevalence but high lethality. In this issue of the Journal, colleagues from the Congenital Heart Surgeons' Society present their data from a registry-based, multi-institutional observational cohort of patients with AAOCA. ${ }^{1}$ The study represents the largest investigation of its kind, with the objective of clearly defining risk factors associated with ischemia or sudden cardiac death (SCD). The devil is in the details, and risk stratification of patients with AAOCA is in part dependent on a clear definition of the anatomic subtype. Anomalous left coronary from the right sinus of Valsalva (AAOLCA) is thought to be associated with SCD; best evidence has supported operation in AAOLCA. ${ }^{2}$ Indeed, most patients presenting with ischemia (57\%) and sudden cardiac events (67\%) were patients with AAOLCA, and ischemia in AAOLCA was associated with an intramural course, high coronary orifice, and a slit-like ostium. In patients with anomalous aortic origin of the right coronary artery from the left sinus (AAORCA), ischemia was associated with a longer intramural course. Some $60 \%$ of patients presenting with ischemia were symptomatic; the remainder were asymptomatic and found to be ischemic through a combination of biomarkers, electrocardiogram, and provocative testing. Disturbingly, there were no anatomic features that distinguished patients with sudden cardiac events from those without. Among patients with sudden cardiac events, the prevalence of AAOLCA and AAORCA was not statistically different. AAORCA does not necessarily represent benign disease.

These data begin to starkly define the challenges we face in caring for patients with $\mathrm{AAOCA}-\mathrm{a}$ low-prevalence, potentially lethal disease in which $40 \%$ of patients do not experience symptoms, and current functional testing exhibits imperfect positive predictive value. ${ }^{3}$ Further, the analysis of patients with ischemia versus those without was performed on only approximately half of those enrolled, so the study may be underpowered to identify some key

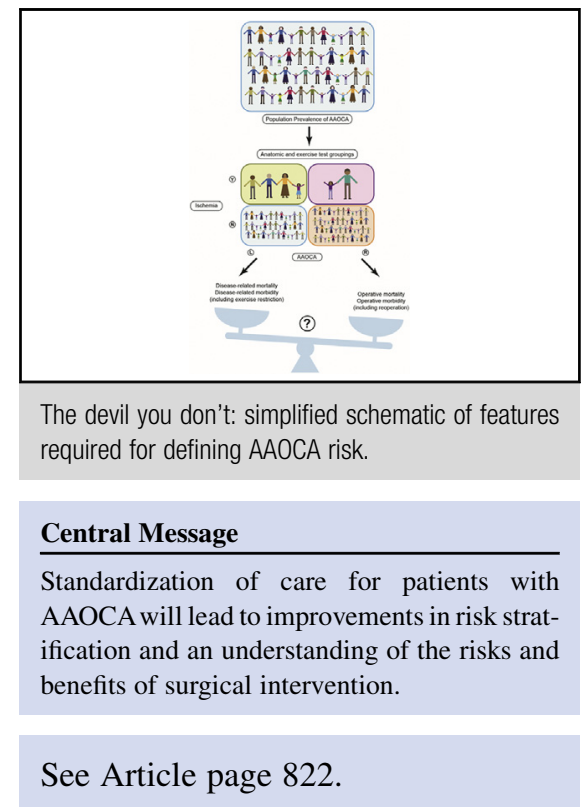

elements defining risk. Finally, the authors demonstrate that $10 \%$ of patients operated for AAOCA were reoperated for coronary ischemia, waving a previously raised red flag that operation for this disease may not always be curative. ${ }^{4}$ In an accurately risk-stratified world, we would know the prevalence and risks of the disease(s) and operation(s) and would operate when the risk of disease outweighs the risk of operation. What has been well demonstrated in many studies is the association of AAOCA with SCD. However, the true incidence of disease(s) remains unknown, and the risk of SCD in AAOCA, particularly AAORCA, remains incompletely understood. ${ }^{5}$ Like much high-quality research, this article raises almost as many questions as it answers. Particularly notable is the significant practice variation and technical hurdles related to imaging and stress testing. Current recommendations suggest anatomic and exercise testing for all patients presenting with AAOCA. To improve the quality of our data, one strategy worth considering would be the adoption of these guidelines within the Congenital Heart Surgeons' Society registry, fortifying future analyses with greater statistical power. The devil that we know may well be better than the devil that we don't.

\section{References}

1. Jegatheeswaran A, Devlin PJ, McCrindle BW, Williams WG, Jacobs ML, Blackstone EH, et al. Features associated with myocardial ischemia in 
anomalous aortic origin of a coronary artery: a Congenital Heart Surgeons' Society study. J Thorac Cardiovasc Surg. 2019;158:822-34.e3.

2. Brothers JA, Frommelt MA, Jaquiss RDB, Myerburg RJ, Fraser CD Jr, Tweddell JS. Expert consensus guidelines: anomalous aortic origin of a coronary artery. J Thorac Cardiovasc Surg. 2017;153:1440-57.

3. Brothers J. Introduction to anomalous origin of a coronary artery. Congenit Heart Dis. 2017;12:600-2.
4. Brothers JA, McBride MG, Seliem MA, Marino BS, Tomlinson RS Pampaloni $\mathrm{MH}$, et al. Evaluation of myocardial ischemia after surgical repair of anomalous aortic origin of a coronary artery in a series of pediatric patients. J Am Coll Cardiol. 2007;50:2078-82.

5. Brothers J, Carter C, McBride M, Spray T, Paridon S. Anomalous left coronary artery origin from the opposite sinus of Valsalva: evidence of intermittent ischemia. J Thorac Cardiovasc Surg. 2010;140:e27-9. 